\title{
Evolução da theoria dos contractos em nossos dias
}

\section{Clovis Bevilaqua}

I. O contracto surgiu, no cosmos juridico, ao se desprender a individualidade do homem da massa geral da collectividade; e, ao mesmo tempo que concorreu para o robustecimento da personalidade, se fez instrumento de harmonia dos interesses, dia a dia mais volumosos e mais largamente distanciados no espaço. Definimol-o, de accordo com o Codigo Civil e qualquer dos Codigos vigentes, sem exceptuar o sovietico, um accordo de vontades para o fim de adquirir, conservar ou extinguir direitos.

A reacção contra o individualismo e, principalmente, as perturbações politicas e sociaes investiram contra essa noção classica, contra a propria figura do acto voluntario gerador de obrigações, arrastando até, na subversão, os proprios Codigos Civis, que se dão como inapplicaveis.

Ha, sem contestação possivel, desorientação na doutrina, da qual, felizmente, a serenidade mental salvou alguns mestres, para conforto do nosso espirito.

Ripert, professor de grande renome, depois de passar em revista a legislação civil de seu paiz (1), exclama desalentado: "Estamos hoje muito desilludidos sobre o valor do contracto. A theoria da autonomia da vontade está desacre-

(1) Traité pratique de droit civil français, de Planiol e RIPERT, em XIV vols. 
ditada pelos philosophos, o liberalismo, abandonado pelos economistas" (2). E accrescenta: "Assistimos á decadencia da soberania do contracto. Na hora actual, esta decadencia accentua-se rapidamente" (3).

$E$ assim é o tom geral do civilista, que tambem nos informa: "Os praticos sabem muito bem que o Codigo Civil já quasi não se applica” (4).

Gaston Morin, decano da Faculdade de Direito da Universidade de Montpellier, entende que não são obrigações contractuaes as que são obra exclusiva de uma das partes e as impostas pela jurisprudencia. "São operações que de contracto apenas têm o nome". As convençõ̃es collectivas são obrigatorias para individuos que não lhes devam o seu consentimento. $\mathrm{O}$ contracto dirigido e o collectivo não são contractos, no sentido exacto do termo. Esse vocabulo esconde, em vez de exprimir, a realidade. Designando operações juridicas desconhecidas na epoca do Codigo, é a applicação do processo das ficções, que tem por fim disfarçar o real novo em conceitos antigos (4-A).

Outro é o ponto de vista do eminente professor Luiz JosSERAND, conselheiro da Corte de Cassação, que, assignalando a evolução no dominio do contracto, considera-a manifestação de movimento de mais longa envergadura, que interessa a todo o direito e da qual resulta que o "negotium juris dos romanos se tornou, ao mesmo tempo, acto privado e acto publico, tendo a liberdade perdido a sua funcção de principio regulador supremo dos contractos" (5). A accumula-

(2) O regimen democratico e o direito civil moderno, tradução de J. Cortezão, S. Paulo, 1937, Saraiva e Cia., p. 179.

(3) Idem, ibidem, p. 272.

(4) Op. cit., p. 433.

(4-a) Revue trimestrielle de droit civil, 1937, vol. 36, p. 550 e 560 .

(5) Revue trimestrielle de droit civil, 1927, p. 3. O autor vê, nesse facto, a realização de idéas de Cosentrni, La riforma della legislazione civile, cuja primeira edição italiana é de 1911. 
ção de capitaes e a concentração de emprezas impuzeram essa mudança. Entre contractantes poderosos e contractantes infimos, desappareceu a liberdade contractual. Era forçoso que interviesse outro poder, para transformar a egualdade theorica, contrariada pelos factos, em egualdade effectiva, com uma politica de regulamentação e intervencionismo, de onde resultou não a morte do contracto, mas a transformação do seu conceito, o phenomeno do dirigismo contractual (6).

Ao contrario do que sustentam outros, pullulam, actualmente, formas novas de contracto. Apenas estes se estandardizam, sem prejuizo do conteudo obrigatorio; com a immixtão dos Poderes Publicos, na vida contractual; attenuação da força circulante do contracto e da constituição de um estado de classe (7).

II. Entre nós, repercutiu esse aspecto da doutrina contractual, e uma das mais notaveis manifestações apparecidas com essa orientação é a de Arthur Rocha, em seu livro Da intervenção do Estado nos contractos concluidos (8). Enfrenta somente um sector do problema, que está preoccupando os juristas europeus; mas discute-o com severidade e penetração, mostrando que as modificações da theoria contractual, exigidas pelo estado actual das coisas, podem ser obtidas pela jurisprudencia, sem quebrar a moldura do Codigo Civil que, no art. 7 da Introducção, lhe offerece os amplos recursos da analogia juridica e dos principios geraes de direito, capazes de submetter á ordem juridica quantas formações sociaes o progresso determinar nas relações de ordem privada.

(6) Revue cit., p. 5 e 6 . Em differentes publicações juridicas tem Josserand exposto estas idéas.

(7) Loco citato, p. 5 a 30.

(8) O livro é de 1932 , e tem por subtitulo - A revisão dos negocios privados e o Codigo Civil. 
$\mathrm{Na}$ legislação tambem se reflectiram as idéas, que se agitam no mundo juridico estrangeiro; mas desarticuladamente, por provisões desconnexas, attendendo a casos ou situações differentes.

III. A tendencia para a socialização do direito privado não é dos nossos dias, após guerra, bolchevismo e estatismo. Sem remontar ás idéas revolucionarias, que precederam ao periodo constructivo de Stammller, Gierke, Dugdit e outros, vulgarizaram-se entre os nossos juristas, como é sabido, as idéas do socialismo juridico, através das obras de Giantúrco, Cimbali D'Aguano, Tortori, Cosentini, Menger, etc.

A linguagem de alguns destes autores é identica á dos que acabam de ser invocados, se attendermos á realidade dos tempos.

MENGer vê na liberdade contractual uma guilhotina, porque não pode ser, realmente, livre aquelle que se acha em posição de inferioridade economica, ou de dependencia, ou forçado pelas necessidades da vida, em face do mais poderoso, ou mais forte (9).

E' de Coviello esta ponderação: "Liberdade sem egualdade é liberdade de um ou de muitos, tyrannia de uma parte e escravidão de outra" (10). E Cosentini, commungando nas mesmas idéas, adeanta: "O Estado não pode nem deve desinteressar-se das relações entre o capitalista e o proletario; isso importaria em abandonar todo o direito das obrigações á força antiracial do egoismo, ao interesse individual do mais poderoso, á acção deleteria da especulação e da concorrencia. Em verdade, emquanto um conjuncto de disposições legislativas não vier refreiar o arbitrio dos privilegiados, um triste estado de coisas se apresenta aos olhos do observador" (11).

(9) Il diritto civile e il proletariato, p. 17.

(10) L'equità nei contratti, p. 7-8.

(11) La riforma della legislazione civile, 1911, p. 297. 
Eis ahi: o reconhecimento da desegualdade economica tornando irrisoria a liberdade contractual, e da necessidade da intervenção dos Poderes Publicos, afim de restabelecer o equilibrio das partes contractantes.

E esse modo de ver se infiltrou na mentalidade commum dos que meditam acerca dos phenomenos economicos e juridicos. Apenas, em nossos dias, a questão adquiriu maior estensão: não se limita a uma classe de individuos, estendese á massa geral da população. E ameaça destruir a organização juridica, sem poder substituil-a por outra, que assegure as condições de vida e desenvolvimento da sociedade.

Aos juristas, como aos homens de Estado e a todos que se interessam pelo progresso social e o bem estar dos individuos, cabe envidar esforços para desfazer a confusão desorientadora, restabelecer a segurança nas relações e reforçar os esteios ethico-juridicos da civilização, adaptando-os, quando necessario, ás situações novas, que a vida social for creando.

IV Em conferencia feita em 1936, na Faculdade de Direito de Paris, sobre o thema - As tendencias modernas do direito das obrigações, o professor Izladits, de Budapest, mostrou mais confiança nas verdades adquiridas do direito, do que os seus collegas francezes aqui invocados. A sua these $\dot{e}$ demonstrar que o moderno direito das obrigações é mais flexivel, mais equitativo, em uma palavra, mais social. No seu pensar, as medidas excepcionaes, tomadas para attender ás perturbações do presente, desapparecerão, com a volta da sociedade ás condições normaes. Certamente algumas dessas medidas exprimem idéas suas e têm valor duravel, como a protecção dos arrendamentos commerciaes e industriaes, a theoria da imprevisão ou impossibilidade economica (12).

A prova de que as metamorphoses politicas não exigem transformação no direito privado, allega o professor hun-

(12) Bulletin trimestriel de la Société de législation comparée, 1937, p. 119 a 135. 
garo, está em que, na Italia fascista, ainda não se operou alteração no direito privado que não possa figurar num Estado democratico; que o projecto official do Codice Civile está escripto num espirito conservador; que o Projecto Grande italiano de Codigo das obrigações, redigido no quinto anno da era fascista (1927), se distingue por seu espirito de moderação, adaptando-se a uma grande democracia e a um Estado totalitario (13).

Podemos accrescentar que o movimento legislativo da America do Sul, relativo ao direito privado, como o Codigo Civil do Perú e o Projecto argentino de Reforma do Codigo Civil, tambem não sentiram necessidade de assentar sobre outras bases as relações de ordem privada.

O Codigo Civil do Perú, no art. 1.328, estatue:

Los contratos son obligatorios en cuanto se haya expresado en ellos, y deben ejecutar-se según las reglas de la buena fe y común intención de las partes.

A Reforma do Codigo Civil argentino dispensou-se de offerecer, na parte dispositiva, uma definição de contracto á semelhança do que fez o legislativo peruano; porém dispõe:

Art. 820 - Las convenciones incluidas en los contratos son obligatorias para las partes y deben ser cumplidas de buenafé. Ellas obligan a lo que está expresado, y a todas las consecuencias virtualmente comprendidas, teniendo en cuenta los usos del lugar.

E' a noção do contracto, que não pode desapparecer, sem que se subverta a ordem social.

V. Ao meu ver a perturbação intellectual, que se reflecte na politica e no direito, ha de passar, afinal, e a vida juri-

(13) Bulletin cit., p. 121 a 122. 
dica retomará o seu andamento normal, em consonancia com o evolver da sociedade, sem que as necessidades novas determinem novas formas de coexistencia humana, ou tenham de romper as bases geraes da estructura juridica.

a) Soçobraria a vida social, se della desapparecessem o contracto, a segurança das relações juridicas e a autonomia da vontade, isto é, a livre actividade das partes nas gerencia dos seus negocios.

Certamente, a lei deve intervir para defender os fracos, que o egoismo dos fortes procura submetter. Sempre o fez, em beneficio dos incapazes, e hoje, com o formidavel desenvolvimento das industrias, vae fazendo mais largamente aos locadores de serviço.

b) A socialização do direito privado ha de ser o equilibrio dos interesses de individuo e os da sociedade, a harmonia das relações entre as classes sociaes; porquanto a sociedade se compõe de individuos e, se o comprimirem ou lhe absorverem a liberdade afogada no grupo social, desapparecerá o elemento activo, de que depende o progresso em todos os sectores da vida, definhará o todo pela debilidade das unidades componentes. $O$ individualismo exaggerado, que aliás não constitue ideal de nenhuma escola, é desorganizador; mas a socialização extremada, que muitos apregoam, é atrophiante. 0 grupo (classe ou nação) é forma social necessaria; mas, á semelhança do organismo animal, se compõe de cellulas, tecidos, apparelhos, que não podem ser desprezados, sem sacrificio do aggregado. E a intervenção dos Poderes Publicos para impedir o abuso do direito, ou para soccorrer os fracos, equilibrando as forças dos contractantes, ou para impedir o collapso de energias uteis, é, em grande parte, movimento em apoio do individuo isolado ou em classe, e poderá ser contra a propria classe, quando esta fôr compressora.

c) Prefaciando a traducção franceza do Codigo das obrigações da Polonia, Henri Capitant refere-se ao periodo 
de nacionalismo exagerado (14), que atravessamos; e, na Allemanha, surgiu a theoria racista do direito. São fructos da conturbação dos espiritos, em consequencia da grande guerra, que recalcou a espiritualidade humana para as camadas inferiores, desde muito transposta pela cultura.

$O$ direito tem base universal, porque é organização da vida social, onde quer que ella se apresente, e aspira á universalidade dos seus preceitos fundamentaes, sem prejuizo de adaptações regionalistas, porque a humanidade é uma só familia e tende para a unidade moral.

d) A applicação e a interpretação das leis pelo Poder Judiciario, dentro do espirito de justiça, da razão juridica e da orientação do direito nacional, devem ter a largueza necessaria, para prover os casos novos e preencher as lacunas do direito escripto, emquanto não sobrevém a reforma exigida pela evolução social.

Ha pouco, Philadelpho Azevedo assignalava a these do Ministro Carlos Maximiliano “de que são offensivas da lei magna os contractos, em que as garantias só cabem a uma das partes, em detrimento da outra; assim, nas vendas com reserva de dominio, a perda da coisa, com todas as prestações já realizadas, apenas pelo inadimplemento da ultima, envolve, para o illustre juiz, um contracto usurario, considerado illicito pela Constituição" (15).

O contracto era aberrante da justiça, da razão juridica, e dos principios dominantes em nossa legislação. Não podia prevalecer, e, muito menos, servir de fundamento a uma acçã̀o penal de apropriação indebita, contra o comprador, que se recusava a restituir o objecto, para cuja acquisição já havia pago todas as prestações menos a ultima. A construcção

(14) Code des obligations de la République de Pologne, 1935, p. VII.

(15) Jornal do Commercio, do Rio de Janeiro, ed. de 30 de dezembro de 1937. 
jurirlica da reserva do dominio, nas vendas a prestações, é, technicamente, viciosa, e, moralmente, condemnavel.

e) No meu sentir, a evolução do direito obrigacional deve ser encaminhada no sentido da flexibilidade dos dispositivos e da equidade das soluções. Insisto no meu pensamento já exposto em outra opportunidade, de que o direito necessita abeberar-se, de mais em mais, de elemento ethico. $\mathrm{E}$ tudo isso dentro das largas e sólidas bases dos principios já definitivamente fixados, porque é essencial para a vida em sociedade a segurança das relações juridicas. Sem essa segurança, sem a estabilidade dos direitos adquiridos, a personalidade individual se dissolve e o edificio social desmorona.

Falando, ha pouco, perante os juristas reunidos no Congresso da Semana Internacional do Direito, o Ministro Mauricio Violette exclamava: "Nossa democracia prefere que o mundo seja construido segundo a lei do consentimento. estamos persuadidos de que seria grande felicidade, se uma idéa tão essencial como a dos contractos fosse elucidada, com regras precisas, que attendessem a certa imprevisibilidade, porém de modo definido e claro, para que cada um ficasse, antecipadamente, informado dos riscos possiveis, na hora em que as vontades se vinculassem" (16).

São as idéas de liberdade individual e de segurança na vida das relações sociaes, que dessas palavras transpiram. A liberdade racionalizada pelo direito justo e a segurança da actividade productiva são condições essenciaes á coexistencia humana, porque a liberdade é força propulsiva, mas, sem a segurança juridica, a sua acção resultará inutil ou de valor precario.

A conciliação dessas duas forças, a liberdade, que se expande, e a segurança que lhe assegura a efficiencia, dentro da ordem juridica, depende, necessariamente, de uma legis-

(16) Bulletin trimestriel de la Société de législation comparée, 1937, julho a setembro, p. 277. 
lação saturada de moral e do sentimento de respeito á personalidade humana.

O conflicto entre a rigidez do principio conservador e garantidor - pacta sunt servanda e a regra excepcional da justiça - rebus sic stantibus, se resolve, na pratica e na jurisprudencia, pela bôa fé na interpretação dos contractos, e, na legislação, pela saturação da moral na vida juridica. 